\title{
Evaluating Collaborative Innovation Ability of School-Enterprise Cooperation
}

\author{
Min Yang \\ School of Management, Jinan University, Guangzhou, China \\ Email: yangm904@126.com
}

Received 25 December 2014; accepted 12 January 2015; published 20 January 2015

Copyright (C) 2015 by author and Scientific Research Publishing Inc.

This work is licensed under the Creative Commons Attribution International License (CC BY). http://creativecommons.org/licenses/by/4.0/

(C) (i) Open Access

\section{Abstract}

This paper mainly evaluates and analyzes the collaborative innovation ability of school-enterprise cooperation through the construction of key evaluation index system and model of the application. First, we construct the general evaluation index system. After screening with characteristics of group decision making method, we get the key evaluation index system. And then, we construct the two-level fuzzy comprehensive evaluation model to evaluate the influence degree of the key indicators. Finally, the practicability with the instance data has been tested. And based on the results of comprehensive evaluation, we carry on the specific two-level analysis of the data on knowledge collaborative innovation ability, technology collaborative innovation ability and information collaborative innovation ability. Through the development degree of every collaborative innovation abilities, the causes and effects of the factors have been analyzed and got.

\section{Keywords}

School-Enterprise Cooperation, Collaborative Innovation Ability, Two-Level Fuzzy Comprehensive Evaluation Model, Characteristics of Group Decision Making Method

\section{Introduction}

Collaborative innovation is a form which derives from resources and above the resources, and the form is created from a combination of different kinds of resources within a certain range. It plays the role in connection among different subjects, besides, it can build internal relation among different parts within a subject, or it can be perceived as joint reconstruction of resources. However, the combination of resources is not only integrating resources simply, but also in depth. As the "2011 Plan” was put forward, university have progressed and developed in knowledge acquisition and practical ability through collaborative learning and innovation with various collaborative subjects. Although talent cultivation boosted greatly, the relation between application degree and 
cultivation effect remains to be tested. Therefore, this paper analyzes collaborative innovation ability of schoolenterprise collaboration to which is paid attention widely at present, and evaluates the degree of collaborative innovation ability between these two subjects through integration of resources. And then, the effect of practical application would be tested by instant data.

\section{The Research Status}

As for the selection of evaluation indexes of collaborative innovation ability of school-enterprise cooperation, Westhesd and Storey [1] created evaluation indicators, which include main research result, research plan, information exchange, special technical equipment, training and the degree of support for school teaching project, to evaluate resource network of school-enterprise cooperation when analyzing links between higher education institutions and high technology firms. Laurson and Ammon Salter [2] analyzed the information resources and knowledge innovation activities of British manufacturing enterprises and universities, indicated that knowledge and information resource of universities is more important than other innovation resources. Moreover, they came up with evaluation indicators like academic report, computer database, technical support and so on, and proved that the most important factor which influences the collaboration ability of enterprise is resource, which is followed by equip- ment, material and component. At present, there are rich research achievements about collaborative innovation ability, which mainly focus on knowledge and technology collaborative innovation. For example, Zhiguo Lu and Zhixiong Liu [3] put forward a multi-level comprehensive evaluation index system of regional innovation ability when evaluating regional technical innovation based on collaborative concept. The index system has four aspects, including basic resources strength, input capacity of technical innovation, output capacity of technical innovation, regional policy and management level. Wei Zhang and Shibin Liu [4] analyzed the way of school-en- terprise cooperation and indicated employees are important links which combine schools and enterprises. Employees' professional qualities are lifeline of firms, so firms need graduates cultivated by schools with practical experience and innovation ability to save cost in production and operation. And the effective way is to transform firms from employers to joint-cultivation organizations. Yibing Fang [5] analyzed the relationship of knowledge interaction between universities and firms and gave measurable knowledge interaction index, number of joint research projects, number of school intellectual property purchased by firms, number of joint published research result, number of academic communication and so on. However, nature of university and enterprise should be taken into consideration during the process of school-enterprise cooperation. In addition, the difference between it and other collaborative innovation should be paid attention to. Zuoming Deng [6] indicated collaborative innovation of school-enterprise is an ongoing process, during which universities are producers of scientific achievement and suppliers of technological products, and enterprises are demanders of technological products and the one who is transforming scientific achievement to productivity. Xiaoxiao Zhu [7] indicated that ability of information mining and analyzing was the key influence factor of development of universities. Daoxian Yang [8] analyzed double cluster problems, industrial cluster and subject cluster, and indicated practical situation should be taken into consideration when analyzing collaborative innovation ability. The practical situation included immeasurability, unknowability and uncertainty of information. Information obtaining has become an important way of collaborative innovation. Haijian Wang [9] analyzed innovation ability of university students and indicated forming information sharing platform and establishing interactive communication mechanism through integrating all kinds of resources in university, which can contribute to increase the collaborative innovation ability of university students.

To sum up, as to selecting evaluation indicators for collaborative innovation ability of school-enterprise, it mainly focus on knowledge innovation and technical innovation to which are especially paid attention from foreign scholars. However, they neglect information resources play an important role in collaborative innovation in nowadays, and information collaborative innovation ability has never been put forwarded by scholars. Thus it can be seen that on the basis of knowledge collaborative innovation ability and technology collaborative innovation ability and in consideration of practical situation of school-enterprise cooperation, effect of information collaborative innovation ability cannot be neglected, so it can be an important index and we should include it into evaluation index system. Therefore, this paper classifies indexes used to evaluate collaborative innovation ability of school-enterprise into three categories: knowledge collaborative innovation ability, technology collaborative innovation ability and information collaborative innovation ability.

In term of selection of evaluation model, domestic scholars used fuzzy comprehensive evaluation model 
widely. Gang Xiang and Jingxia Fan [10] analyzed the performance evaluation of strategic alliances of technical innovation, and applied fuzzy comprehensive evaluation model to instance data. But they only gave performance scores, and did not evaluate every indicator of index system further. Ling Zhang and Tongxu Liu [11] only created technical innovation risk evaluation system and two-level fuzzy comprehensive evaluation model when evaluating technical innovation risk evaluation of school-enterprise cooperation, but did not combine the evaluation system to test and analyze effectiveness of the model. Although Rong Liu and Keyi Wang [12] applied fuzzy comprehensive evaluation system to instance in research, it lacked concrete analysis of the instance computation and just explained comprehensive innovation risk simply instead.

Based on former research, this paper uses two-level fuzzy comprehensive evaluation model to evaluate collaborative innovation ability of school-enterprise. On the one hand, we quantitatively analyzed effect of technology collaborative innovation ability. On the other hand, we make information collaborative innovation ability be a part of evaluation index system, because we think it is an important way to increase benefits of both sides and decrease uncertainty of obtaining information.

All in all, there are three main differences between this paper and other researches as follows. Firstly, we include information collaborative innovation ability into our evaluation index system to show its importance in school-enterprise cooperation at present and it's never been put forwarded by scholars. Secondly, we use twolevel fuzzy comprehensive evaluation model which can combine qualitative indexes and quantitative indexes, making up for the deficiency that qualitative indexes cannot be measured in other models. Thirdly, this paper applies evaluation system to instance data, covering the shortage that current studies of fuzzy comprehensive evaluation lack application to instance and testing.

\section{Construction of General Evaluation Index System of Collaborative Innovation Ability of School-Enterprise}

\subsection{General Evaluation Index System of Collaborative Innovation of School-Enterprise}

Based on the research results at home and abroad, this paper classifies indexes used to evaluate collaborative innovation ability of school-enterprise into three categories: knowledge collaborative innovation ability, technology collaborative innovation ability and information collaborative innovation ability. Among these three categories, information collaborative innovation ability has never been put forwarded by scholars, because they classified it into knowledge collaborative innovation ability. In consideration of the need for the development of information era and information that is playing an increasing important role in universities and enterprises, this paper presents information collaborative innovation ability with knowledge collaborative innovation ability and technology collaborative innovation ability. Furthermore, this paper extracts typical indexes to value it according to practical situation, enriching narrow connotation of information, extending it to degree of information sharing and opening. In accordance to this framework, these three main factors are broke up into eighteen subfactors, as shown in Table 1.

\subsection{Screening Key Evaluation Index System Based on Characteristics of Group Decision Making Method}

The construction of evaluation index system follows principles of simpleness, independence, representativeness, objectivity and feasibility. In screening evaluation indexes, we adopt questionnaire survey. We invite twelve experts from state institutions, companies, universities, research institutions etc. who have participated in researching collaborative innovation ability of school-enterprise. We design five degrees for key evaluation indexes, namely very unimportant, unimportant, important, very important, and vitally important, and the corresponding score is 1 , $2,3,4$, and 5 . We take evaluation index system of knowledge collaborative innovation ability as an example and give its rating table, as shown in Table 2.

Using characteristics of group decision making method and applying MATLAB, we got the largest simple eigenvalue which equals 985.8333 , and eigenvector is $0.5421,0.2955,0.4865,0.2692,0.2312,0.5062$. After the unitization, we get $0.2326,0.1268,0.2087,0.1155,0.0992,0.2172$. Then, we got rid of evaluation indexes whose significance are less than 0.2 , and afterwards, $U_{11}, U_{13}$ and $U_{15}$ remained. According to the same method, we figured out the corresponding eigenvalue and eigenvector of other two first class indicators successively, which are 959.7494 and $0.2223,0.5220,0.5311,0.5041,0.2796,0.2524,996.3882$ and $0.2840,0.2114,0.5134$, 
Table 1. Evaluation index system of collaborative innovation ability of school-enterprise.

\begin{tabular}{|c|c|c|c|}
\hline System & Factors & Sub-factors & \\
\hline \multirow{18}{*}{$\begin{array}{l}\text { Evaluation index system of } \\
\text { collaborative innovation of } \\
\text { school-enterprise }\end{array}$} & \multirow{6}{*}{$\begin{array}{c}\text { Knowledge } \\
\text { collaborative } \\
\text { innovation ability }\end{array}$} & effect of order-oriented talent cultivation & $U_{11}$ \\
\hline & & teaching-level of university & $U_{12}$ \\
\hline & & number of school intellectual property purchased by firm & $U_{13}$ \\
\hline & & popularity of university & $U_{14}$ \\
\hline & & number of joint published research result & $U_{15}$ \\
\hline & & knowledge level of firm employees & $U_{16}$ \\
\hline & \multirow{6}{*}{$\begin{array}{c}\text { Technology } \\
\text { collaborative } \\
\text { innovation ability }\end{array}$} & advanced degree of firm equipment & $U_{21}$ \\
\hline & & exchange of research personnel & $U_{22}$ \\
\hline & & number of research projects & $U_{23}$ \\
\hline & & financial support for university projects from firm & $U_{24}$ \\
\hline & & economic benefit of firm & $U_{25}$ \\
\hline & & practical ability of university & $U_{26}$ \\
\hline & \multirow{6}{*}{$\begin{array}{c}\text { Information } \\
\text { collaborative } \\
\text { innovation ability }\end{array}$} & update frequency of information resources & $U_{31}$ \\
\hline & & information capacity of university & $U_{32}$ \\
\hline & & academic communication etc. & $U_{33}$ \\
\hline & & opening degree of information platform & $U_{34}$ \\
\hline & & degree of information requirements & $U_{35}$ \\
\hline & & number of feedback of research result information & $U_{36}$ \\
\hline
\end{tabular}

Table 2. Experts rating table for screening key evaluation index system of knowledge collaborative innovation ability.

\begin{tabular}{|c|c|c|c|c|c|c|}
\hline & $U_{11}$ & $U_{12}$ & $U_{13}$ & $U_{14}$ & $U_{15}$ & $U_{16}$ \\
\hline $\mathrm{S}_{1}$ & 5 & 5 & 5 & 1 & 2 & 4 \\
\hline $\mathrm{S}_{2}$ & 5 & 2 & 4 & 5 & 3 & 5 \\
\hline $\mathrm{S}_{3}$ & 4 & 3 & 5 & 2 & 1 & 5 \\
\hline $\mathrm{S}_{4}$ & 5 & 3 & 4 & 2 & 3 & 5 \\
\hline $\mathrm{S}_{5}$ & 5 & 3 & 4 & 2 & 3 & 4 \\
\hline $\mathrm{S}_{6}$ & 5 & 2 & 4 & 3 & 2 & 5 \\
\hline $\mathrm{S}_{7}$ & 5 & 1 & 5 & 2 & 1 & 4 \\
\hline $\mathrm{S}_{8}$ & 5 & 3 & 4 & 3 & 2 & 5 \\
\hline $\mathrm{S}_{9}$ & 5 & 2 & 4 & 3 & 1 & 5 \\
\hline $\mathrm{S}_{10}$ & 5 & 3 & 5 & 3 & 2 & 4 \\
\hline $\mathrm{S}_{11}$ & 5 & 3 & 4 & 1 & 3 & 4 \\
\hline $\mathrm{S}_{12}$ & 5 & 2 & 5 & 2 & 3 & 5 \\
\hline
\end{tabular}

0.5305, 0.2573, 0.5133. And then, we unitized the eigenvectors, getting 0.0962, 0.2258, 0.2298, 0.2181, 0.1209, 0.1092 and $0.1229,0.0915,0.2223,0.2297,0.1114,0.2222$. Hence, the most significant evaluation indexes remained are $U_{22}, U_{23}, U_{24}$ and $U_{33}, U_{34}, U_{36}$. Finally, we constructed evaluation index system of collaborative innovation ability, as shown in Table 3. 
Table 3. Screened evaluation index system of collaborative innovation ability of school-enterprise.

\begin{tabular}{|c|c|c|c|}
\hline $\begin{array}{l}\text { Evaluation } \\
\text { objective }\end{array}$ & $\begin{array}{l}\text { First class } \\
\text { index }\end{array}$ & Second class index & Explanation \\
\hline \multirow{9}{*}{$\begin{array}{l}\text { Evaluation index } \\
\text { system of } \\
\text { collaborative } \\
\text { innovation of } \\
\text { school-enterprise }\end{array}$} & \multirow{3}{*}{$\begin{array}{c}\text { Knowledge } \\
\text { collaborative } \\
\text { innovation } \\
\text { ability }\end{array}$} & $U_{11}$ : effect of order-oriented talent cultivation & $\begin{array}{l}\text { satisfaction of firm about students in contractual } \\
\text { program with university }\end{array}$ \\
\hline & & $\begin{array}{l}U_{13} \text { : umber of school intellectual property } \\
\text { purchased by firms }\end{array}$ & $\begin{array}{l}\text { number of contracts of purchasing patents and } \\
\text { intellectual property between university and firms }\end{array}$ \\
\hline & & $U_{15}:$ umber of joint published research result & actual number of joint published research result \\
\hline & \multirow{3}{*}{$\begin{array}{c}\text { Technology } \\
\text { collaborative } \\
\text { innovation } \\
\text { ability }\end{array}$} & $U_{22}$ : exchange of research personnel & $\begin{array}{l}\text { times of contacts between research personnel from } \\
\text { university and firm in a certain period of time }\end{array}$ \\
\hline & & $U_{23}:$ umber of research projects & number of official joint research projects \\
\hline & & $U_{24}$ : financial support for university projects from firms & financial support for university projects from firms \\
\hline & \multirow{3}{*}{$\begin{array}{c}\text { Information } \\
\text { collaborative } \\
\text { innovation } \\
\text { ability }\end{array}$} & $U_{33}:$ academic communication etc. & $\begin{array}{l}\text { total of information communication activities hold } \\
\text { by university or firm, as academic communication, } \\
\text { discussion, symposium }\end{array}$ \\
\hline & & $U_{34}$ : opening degree of information platform & $\begin{array}{l}\text { opening degree of internal information on network } \\
\text { resource sharing platform of university and firm }\end{array}$ \\
\hline & & $\begin{array}{c}U_{36}: \text { number of feedback of research } \\
\text { result information }\end{array}$ & $\begin{array}{c}\text { number of application feedback of joint completed } \\
\text { project }\end{array}$ \\
\hline
\end{tabular}

\section{Construction of Two-Level Fuzzy Comprehensive Evaluation Model of Collaborative Innovation Ability of School-Enterprise}

Among screened key evaluation indexes, there are two qualitative indexes need to be quantized, which are effect of order-oriented talent cultivation and opening degree of information platform. To guarantee research date scientific and rigorous, we convert quantized indexes into indexes rating number. According to the principle of statistics, we standardize quantized indexes and use them to evaluate the model by fuzzy comprehensive evaluation.

$U$ set stands for collaborative innovation ability of school-enterprise, $U=\left(U_{1}, U_{2}, U_{3}\right) . U_{1}, U_{2}, U_{3}$ stand for knowledge collaborative innovation ability, technology collaborative innovation ability, and information collaborative innovation ability respectively. $U_{i j}$ stands for second class index, $U_{i j}=\left\{U_{i 1}, U_{i 2}, U_{i 3}\right\}$, means the $j$ th sub-factor which influence $U_{i}$.

1) Construct rating set of evaluation indexes

Suppose rating set is $V, V=\left(V_{1}, V_{2}, \cdots, V_{j}\right),(j=1,2, \cdots, m)$, and $V_{j}$ stands for evaluation results. The number of evaluation degree commonly is 4 to 9 . This paper supposes $m=5, V=\left(V_{1}, V_{2}, V_{3}, V_{4}, V_{5}\right)$. And the rating of collaborative innovation ability means $V=$ \{very strong, strong, average, weak, very weak .

2) Confirm weight of evaluation indexes

This paper uses Analytic Hierarchy Process (AHP) to set weight for evaluation indexes of collaborative innovation ability, comparing influence degree for model of every two indexes. We use Satty's 1 to 9 rule to judge the significance of every sub-factors, and use $a_{i j}$ to show it, $i, j=(1,2, \cdots, n)$. If $a_{i j}>1$, it means the influence degree of the ith sub-factor is stronger than that of the jth sub-factor; on the contrary, if $a_{i j}<1$, it means the influence degree of the $j$ th sub-factor is stronger than that of the $i$ th sub-factor, and $a_{i j}=1 / a_{j i}$. After pairwise comparison, we can get the pairing comparative matrix $A=\left(a_{j i}\right)_{n \times n}$, and test its consistency. If it passed the test, then we figured out the corresponding eigenvalues and eigenvectors. After standardizing the eigenvectors, we got the fuzzy weight vector $w=\left(w_{1}, w_{2}, w_{3}\right), \sum w_{i}=1, i=1,2,3$.

3) Construct two-level fuzzy comprehensive evaluation model

- one-level evaluation model

$W=\left(W_{1}, W_{2}, W_{3}\right)=\left(W_{i 1}, W_{i 2}, W_{i 3}\right), i=1,2,3$

$V=\left(V_{1}, V_{2}, V_{3}, V_{4}, V_{5}\right)$

- one-level evaluation matrix

$$
R u_{i}=\left[\begin{array}{l}
R_{11}, R_{12}, R_{13}, R_{14}, R_{15} \\
R_{21}, R_{22}, R_{23}, R_{24}, R_{25} \\
R_{33}, R_{32}, R_{33}, R_{34}, R_{35}
\end{array}\right]
$$


Construct one-level multifactorial evaluation model: $B u_{i}=W u_{i} \times R u_{i},(u, i=1,2,3), R u_{i}$ is the subjection degree of $U_{i j}$ to rating level $\mathrm{V}$.

- two-level evaluation model

We can get two-level evaluation matrix from the result of one-level evaluation, namely $R=\left[\begin{array}{l}R_{U 1} \\ R_{U 2} \\ R_{U 3}\end{array}\right]$. Among

it, $R_{u 1}, R_{u 2}, R_{u 3}$ are evaluation vectors of $U_{1}, U_{2}, U_{3}$ respectively.

Construct two-level multifactorial evaluation model: $B=W_{i} \times R,(i=1,2,3)$, B is the subjection degree of $U_{i}$ to rating level V.

\section{Case Analysis}

\subsection{Model Application}

We evaluate collaborative innovation ability of a school-enterprise cooperation in Heilongjiang province. The enterprise is a leading company in Heilongjiang, engaged in processing agricultural products. The main business of this enterprise is intensive processing of agricultural products and it also devotes itself to products research and development. It has advanced production line in domestic and powerful warehousing facilities, and it is paying effort to perfect its technical R\&D system. The university cooperating with it is a provincial key university, with graduate school and postdoctoral research station having strong subject basis and overall strength. We got data of quantitative indexes in evaluation index system through field research and interview. We use Delphi method and Analytic Hierarchy Process to get the quantified data from qualitative indexes. And then, we standardize the quantified data to get the final data of evaluation index system.

Weight vector of first class index: $\left(W_{1}, W_{2}, W_{3}\right)=(0.24,0.56,0.20)$

Weight vector of second class index: $\left(W_{11}, W_{12}, W_{13}\right)=(0.34,0.38,0.28),\left(W_{21}, W_{22}, W_{23}\right)=(0.45,0.23,0.32)$, $\left(W_{31}, W_{32}, W_{33}\right)=(0.35,0.40,0.25)$

Construct one-level fuzzy comprehensive evaluation matrix

$$
R_{u 1}=\left[\begin{array}{l}
0.1,0.3,0.3,0.2,0.1 \\
0.1,0.1,0.2,0.4,0.2 \\
0.1,0.3,0.3,0.2,0.1
\end{array}\right] \quad R_{u 2}=\left[\begin{array}{l}
0.3,0.3,0.2,0.1,0.1 \\
0.2,0.3,0.3,0.1,0.1 \\
0.2,0.3,0.2,0.2,0.1
\end{array}\right] \quad R_{u 3}=\left[\begin{array}{l}
0.1,0.4,0.3,0.1,0.1 \\
0.2,0.3,0.2,0.2,0.1 \\
0.1,0.1,0.3,0.3,0.2
\end{array}\right]
$$

Since $B u_{i}=W u_{i j} \times R u_{i j}(i, j=1,2,3)$, we got one-level comprehensive evaluation results:

$$
\begin{aligned}
& B_{U 1}=(0.100,0.224,0.262,0.276,0.138) \\
& B_{U 2}=(0.245,0.300,0.223,0.132,0.100) \\
& B_{U 3}=(0.140,0.285,0.260,0.190,0.125)
\end{aligned}
$$

And then we got two-level comprehensive evaluation matrix:

$$
R=\left[\begin{array}{l}
0.100,0.224,0.262,0.276,0.138 \\
0.245,0.300,0.223,0.132,0.100 \\
0.140,0.285,0.260,0.190,0.125
\end{array}\right]
$$

Since $B=W_{i} \times R$, we got two-level comprehensive evaluation result:

$$
B=(0.18920,0.27876,0.23976,0.17816,0.11412)
$$

From this, we got a set of rating set to evaluate the model. To have a more intuitive understanding, we quantified it. Setting rating set $V=(100,80,60,40,20)^{\mathrm{T}}$, so the quantified value is:

$$
U=B V=(0.18920,0.27876,0.23976,0.17816,0.11412) \times(100,80,60,40,20)^{\mathrm{T}}=65.0152
$$

As we can see from the calculation results, the collaborative innovation ability of this school-enterprise cooperation is on an average level. To analyze collaborative innovation ability further, we uniformized fuzzy vectors. 
On the basis of weighted average principle $U_{i}=\frac{\sum_{j=1}^{m} b_{j}^{k} \cdot j}{\sum_{j=1}^{m} b_{j}^{k}}$, we calculated and got: knowledge collaborative innovation ability is 56.06 , technology collaborative innovation ability is 74.20 , and information collaborative innovation ability is 64.82 .

\subsection{Analysis of Case Results}

\subsubsection{First Class Evaluation}

Since the result of first class evaluation is 65.0152 which we figured out in former part, we can know the cooperation between the university and the firm is not very mature. In general, the cooperation brought some economic benefit to the firm and boosted its competitiveness and comprehensive strength. For the university, the cooperation contributed to increase its research ability and popularity. However, the cooperation didn't maximize the advantage of collaborative innovation.

\subsubsection{Second Class Evaluation}

1) Knowledge collaborative innovation ability is 56.06, which is at a low level. The main reason is that knowledge innovation often needs a certain amount of cost of time and funds. And compared with the investment in technology innovation, the return of short-term benefit of knowledge investment is not obvious, which leads to the firm thought little of cultivation of knowledge innovation ability. And the investment balance between the two sides is related to firm's size, strategic goals and leaders' horizon. The company with large scale, specific strategic plan and leaders valuing long-term benefit, often attaches importance to the cultivation of knowledge innovation ability. In our case, the university and the firm are located in Heilongjiang province which is far from most provinces of China, so the degree of economic development is restricted. In addition, the firm is a middle-sized technical production and processing enterprise, so its operation with the university shows strong technology collaborative innovation ability and weak knowledge collaborative innovation ability.

2) Technical collaborative innovation ability is 74.20 , which is at a high level. The reason is that this firm aimed at maximizing profit, regarding technology as the main factor that drives the firm to develop fast. In market competition, advanced technology can guarantee the firm to be the leader of its industry, win in enterprise competition, and attain high margin. The firm in case is an agricultural products processing enterprise, having strong demand for technology innovation, because it focuses on intensive technical processing. Therefore, it invested in technology constantly to ensure its market share and position in industry.

3) Information collaborative innovation ability is 64.82 , which is consistent with general collaborative innovation ability. The reason is that high degree of informationization and various way of information exchange and the effect of applying information resources are accepted by a lot of institutions. As the features of information acquisition, on one hand, both firm and university can acquire and share information and get to know latest information and policies easily. On the other hand, complementary advantages of two sides help to realize innovation.

\section{Conclusions}

We can know influence degree of key evaluation indexes to cooperation of school-enterprise in detail through evaluating and analyzing collaborative innovation ability of school-enterprise. And how knowledge, technology and information collaborative innovation ability developed in school-enterprise cooperation can be obtained.

Conclusions of this paper are:

- Collaborative innovation ability of school-enterprise cooperation is mainly affected by knowledge, technology and information collaborative innovation ability.

- Cultivating knowledge collaborative innovation ability needs large cost of time and funds, and it is restricted to enterprise scale, strategic goal and leader's horizon, and it is a long-term investment. Technology collaborative innovation ability is restricted to business scope, industrial competition. It helps to realize short-term goal, so the leaders generally attach importance to it and invest more in it. Information collaborative innova- 
tion ability is the informationized product of social resources, and it is playing an increasing important role in the development of universities and enterprises. Information collaborative innovation ability can be boosted via suitable ways of information obtaining, and both universities and firms can attain to the aim of mutual advantages and mutual development.

\section{References}

[1] Westhead, P. and Storey, D.J. (1995) Links between Higher Education Institutions and High Technology Firms. Omega, 23, 345-360. http://dx.doi.org/10.1016/0305-0483(95)00021-F

[2] Laurson, K. and Salter, A. (2004) Searching High and Low: What Types of Firms Use Universities as a Source of Innovation. Research Policy, 33, 1201-1215. http://dx.doi.org/10.1016/j.respol.2004.07.004

[3] Lu, Z.G. and Liu, Z.X. (2004) Multilevel Fuzzy Comprehensive Evaluation of Regional Innovation Ability. Science and Technology of West China, 8, 3-4.

[4] Zhang, W. and Liu, S.B. (2008) Enterprise Grand Strategic Model: New Ideas for Enhance School-Enterprise Cooperation. Research of Higher Engineering Education, 1, 71-75.

[5] Fang, Y.B. and Fan, X. (2008) An Empirical Study on Knowledge Interactions between Universities and Enterprises Based on Regional Innovation System, Enterprise. $R$ \& D Management, 20, 110-117.

[6] Deng, Z.M. (2013) Human Resource Reserve and School-Enterprise Cooperation. Journal of Changchun Normal University (Humanities and Social Sciences), 11, 104-106.

[7] Zhu, X.X. (2013) Reconstruction from the Reference to the Knowledge Consulting Service Ability. Library and Information Service, 57, 67-71.

[8] Yang, D.X. (2012) Research of Evaluate Method for Subject Clusters and Industrial Clusters Cooperative Innovation Ability. Science \& Technology Progress and Policy, 29, 132-136.

[9] Wang, H.J. (2012) Cultivating the Synergetic Innovation Ability of College Students Based on the Synergetic Innovation Thought. Journal of China University of Petroleum (Edition of Social Sciences), 3, 105-108.

[10] Xiang, G. and Fan, J.X. (2012) Evaluating the Performance of Technology Innovation Strategic Alliance. Technoeconomics \& Management Research, 12, 27-30.

[11] Zhang, L. and Liu, T.X. (2010) Appraisal on Risk in Technology Innovation of the University and the Enterprise Cooperation. Science Economy Society, 28, 86-89.

[12] Liu, R. and Wang, K.Y. (2009) Multi-Level Fuzzy Comprehensive Evaluation Model for Enterprise Cooperation Innovation Risk and Its Application. Science-Technology and Management, 4, 132-135. 
Scientific Research Publishing (SCIRP) is one of the largest Open Access journal publishers. It is currently publishing more than 200 open access, online, peer-reviewed journals covering a wide range of academic disciplines. SCIRP serves the worldwide academic communities and contributes to the progress and application of science with its publication.

Other selected journals from SCIRP are listed as below. Submit your manuscript to us via either submit@scirp.org or Online Submission Portal.
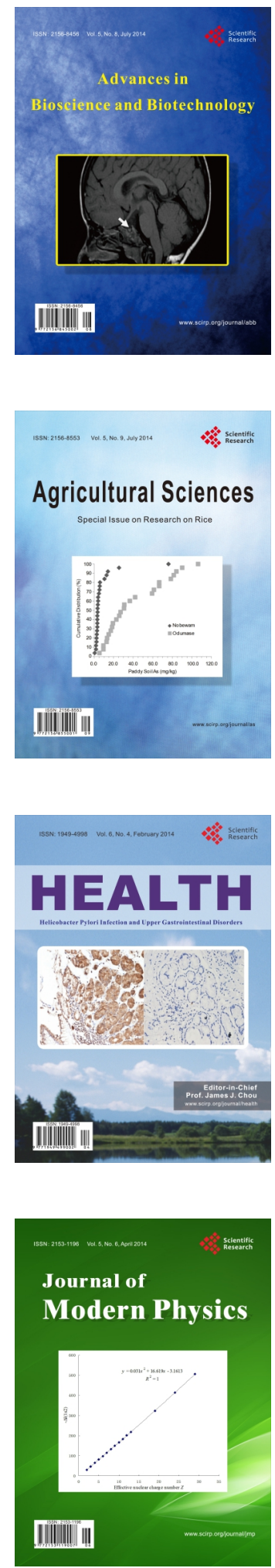
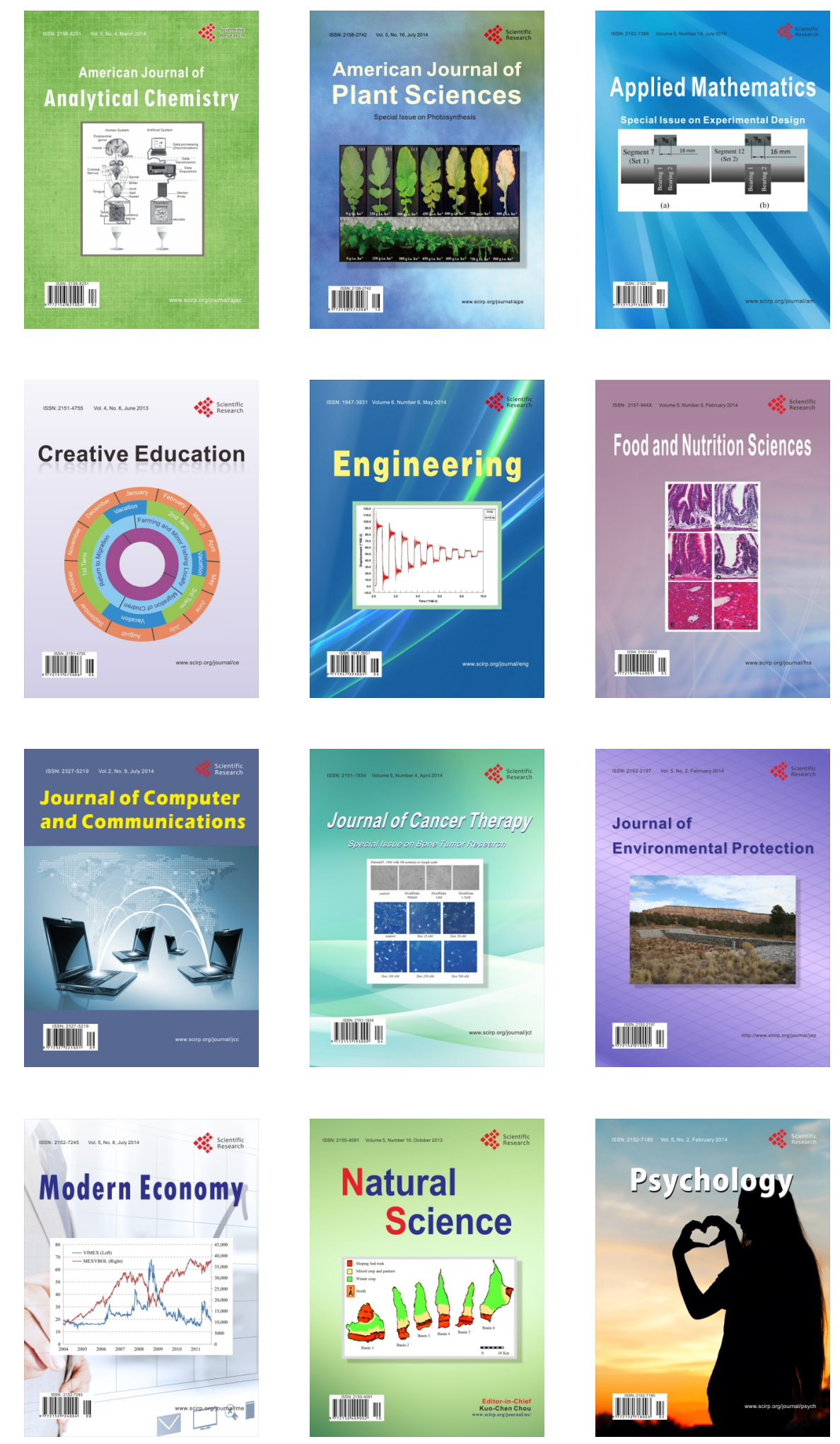